\title{
Comportamento hidrodinâmico de um reator Upflow Anaerobic Hybrid (UAHB)
}

Para o estudo computacional do comportamento de um reator Upflow Anaerobic Hybrid (UAHB) foram utilizadas três variações do tempo de detenção hidráulica (TDH), sendo considerados como parâmetros da simulação as velocidades do fluido, a viscosidade do fluido e as densidades do fluido e do lodo. Pelas simulações realizadas foi possível observar que aproximadamente $24 \%$ do fluido se encontra com velocidade inferior a 3,48x10-6 m.s -1 com TDH de 4 horas, $1,74 \times 10-6$ m.s- 1 na simulação com TDH de 8 horas e 1,16×10-6 m.s-1 na simulação com TDH de 12 horas, sendo indicativo de zonas mortas no reator. E com os perfis de velocidade foi verificado que os maiores valores ocorrem na faixa de entrada e saída do reator, fenômenos estes que podem ter sido influenciados devido à presença de lodo nas simulações, uma vez que muitos estudos não o levam em consideração, mas que são importantes porque podem alterar os caminhos percorridos pelo fluido dentro do reator.

Palavras-chave: CFD; Reator UAHB; TDH; Velocidade; Lodo.

\section{Hydrodynamic behavior of an Upflow Anaerobic Hybrid Reactor (UAHB)}

\begin{abstract}
For the computational study of the behavior of an Upflow Anaerobic Hybrid (UAHB) reactor, three variations of the hydraulic detention time (TDH) were used being considered as parameters of the simulation the fluid velocities, the fluid viscosity and the fluid and sludge. Through the simulations carried out it was possible to observe that approximately $24 \%$ of the fluid is at a speed below $3.48 \times 10-6$ ms-1 with 4-hour HRT, $1.74 \times 10-6$ ms-1 in the simulation with 8-hour and 1 HRT, 16x10-6 ms-1 in the 12-hour TDH simulation, indicating dead zones in the reactor. And with the speed profiles it was verified that the highest values occur in the input and output range of the reactor, phenomena that may have been influenced due to the presence of sludge in the simulations, since many studies do not take it into consideration but they are important because they can change the paths taken by the fluid inside the reactor.
\end{abstract}

Keywords: CFD; UAHB reactor; TDH; Speed; Sludge.

\section{Topic: Engenharia Ambiental}

Reviewed anonymously in the process of blind peer.
Received: 10/11/2020

Approved: 15/02/2021
Guilherme de Paula (iD

Universidade Tecnológica Federal do Paraná, Brasil http://lattes.cnpq.br/3217198672162627

http://orcid.org/0000-0003-1928-1677

guilhermeedep@gmail.com

Flávia Aparecida Reitz Cardoso (iD

Universidade Tecnológica Federal do Paraná, Brasil

http://lattes.cnpq.br/2663975071704461

http://orcid.org/0000-0002-0432-9191

flaviareitz@gmail.com

Flávia Vieira da Silva Medeiros (iD

Universidade Tecnológica Federal do Paraná, Brasil

http://lattes.cnpq.br/8298141172237555

http://orcid.org/0000-0001-6490-8876

flaviavs@gmail.com
Eudes José Arantes id

Universidade Tecnológica Federal do Paraná, Brasil

http://lattes.cnpq.br/5368039952110556

http://orcid.org/0000-0002-7684-3069

eudesarantes@utfpr.edu.br
Referencing this:

PAULA, G.; CARDOSO, F. A. R.; MEDEIROS, F. V. S.; ARANTES, E. J.. Comportamento hidrodinâmico de um reator Upflow Anaerobic Hybrid (UAHB). Natural Resources, v.11, n.1, p.56-61, 2021. DOI: http://doi.org/10.6008/CBPC2237-9290.2021.001.0008 


\section{INTRODUÇÃO}

O lançamento de efluentes brutos em corpos d'agua causa diversos impactos ao meio ambiente, sobretudo a vida aquática. $\mathrm{O}$ tratamento adequado e eficiente desses efluentes é primordial para reduzir os impactos provocados. Dentre as alternativas de tratamento destaca-se o tratamento anaeróbio, que consiste na degradação da matéria orgânica por meio de micro-organismos anaeróbios, que convertem a matéria orgânica complexa em metano, gás carbônico, água, gás sulfídrico e amônia, assim como em novas células bacterianas (CHERNICHARO, 1997).

Nesse processo são utilizados os reatores UASB (Upflow Anaerobic Sludge Blanket), porém, por apresentar algumas limitações, como um maior potencial de formação de escuma e uma dificuldade maior na transferência de massa, algumas modificações são necessárias para aumentar a sua eficiência. Sendo assim, o reator anaeróbio híbrido (UAHB) foi desenvolvido para atender essas necessidades, sendo constituído de um fluxo ascendente do afluente por meio de um leito denso de lodo, localizado na parte inferior do reator e de um leito estacionário, contendo material suporte para adesão celular (GUIOT et al., 1984; SILVA, 2018; KENNEDY et al., 1986).

Diante do uso crescente desses reatores no tratamento de efluentes, surge a necessidade do entendimento de seu comportamento hidrodinâmico. Para isso, uma ferramenta que vem sendo muito utilizada é a Fluidodinâmica Computacional (Computational Fluid Dynamics - CFD). Essa ferramenta aplica conceitos de Dinâmica dos Fluidos, que visa o entendimento do comportamento do fluído dentro do reator por meio do estudo do seu escoamento e da influência que sofre diante de reações químicas e transferência de calor e massa; de matemática, que representa o comportamento do fluído por meio das equações; e da computação, que tem por finalidade realizar o cálculo das equações matemáticas por meio de simulações numéricas (TU et al., 2008).

Face a estas considerações, o objetivo do estudo foi avaliar o comportamento hidrodinâmico de um reator UAHB por meio da ferramenta de fluidodinâmica computacional.

\section{METODOLOGIA}

Foi utilizado como base do estudo um reator de bancada do tipo UAHB (Figura 1) com volume útil de 21 L, utilizado para mensurar medidas para o desenho da geometria no software Ansys - CFX 19.2 (Figura 2).

A partir da geometria desenhada, foi criada uma malha com 190615 elementos com cerca de $1 \mathrm{e}^{-2} \mathrm{~m}$ (Figura 3) para a condução da solução das equações do movimento do fluído simulado ao longo do reator. Após essa etapa, foram inseridas as condições de contorno, o que permitiu, por fim, a execução da simulação do comportamento do fluido por meio de ferramentas de fluidodinâmica computacional.

Para o estudo computacional foram utilizadas três variações do tempo de detenção hidráulica (TDH), sendo considerados como parâmetros da simulação as velocidades do fluido, a viscosidade do fluido e as densidades do fluido e do lodo (Tabela 1). Com resultados obtidos, realizaram-se comparações com bibliografia relacionada ao tema. 


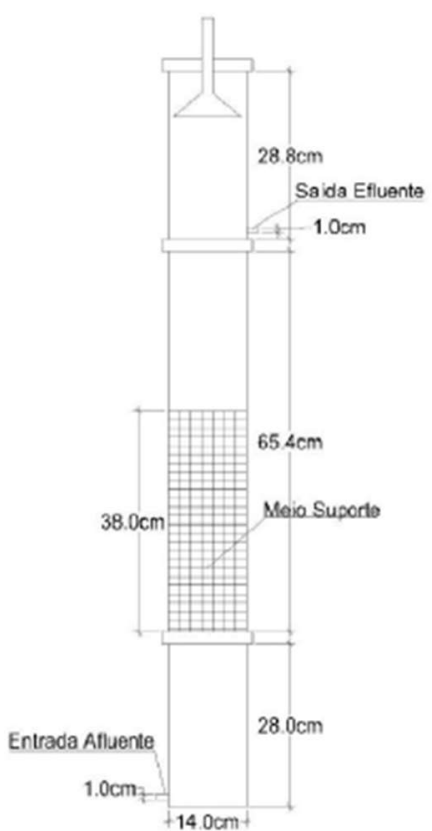

(a)

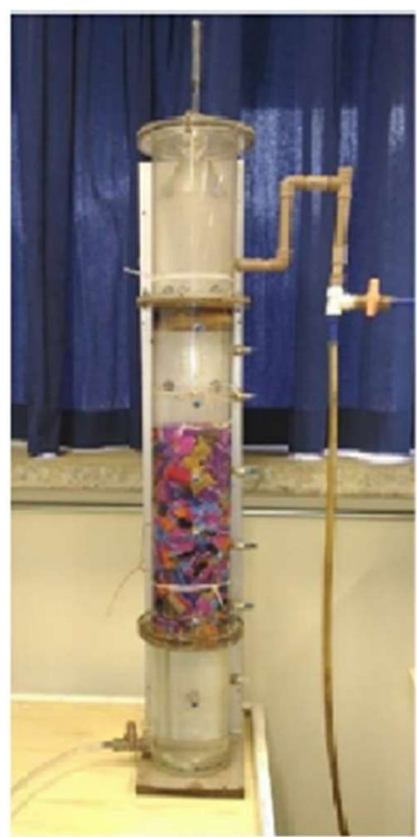

(b)

Figura 1: a) Desenho esquemático do reator UAHB em escala de bancada. b) Foto do reator UAHB Fonte: Silva (2018).
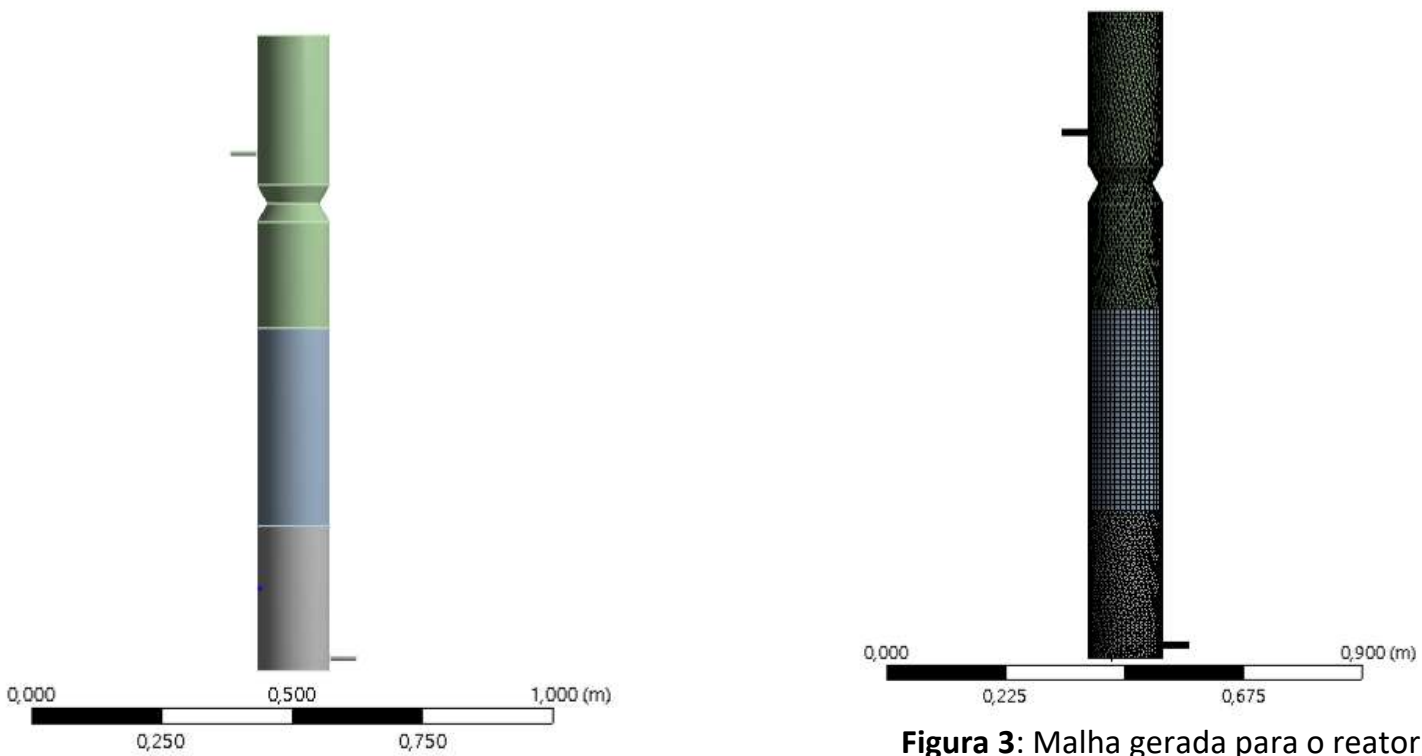

Figura 3: Malha gerada para o reator

Figura 2: Geometria do reator UAHB

Tabela 1: Parâmetros utilizados para simulação no software com os diferentes TDH.

\begin{tabular}{l|l|l|l}
\hline Parâmetro & \multicolumn{2}{l}{ TDH } & $\mathbf{1 2}$ \\
\cline { 2 - 4 } & $\mathbf{4}$ & $\mathbf{8}$ & 0,0052 \\
\hline Velocidade de entrada do fluido $\left(\mathrm{m}_{\mathrm{s}} \mathrm{s}^{-1}\right)$ & 0,0156 & 0,0078 & 0,001 \\
\hline Viscosidade dinâmica do fluido $\left(\mathrm{m}_{\mathrm{s}}^{-1}\right)$ & 0,001 & 0,001 & 1000 \\
\hline Densidade do fluido $\left(\mathrm{Kg} \cdot \mathrm{m}^{-3}\right)$ & 1000 & 1000 & 1460 \\
\hline Densidade do lodo $\left(\mathrm{Kg} \cdot \mathrm{m}^{-3}\right)$ & 1460 & 1460 & \\
\hline
\end{tabular}

\section{RESULTADOS E DISCUSSÃO}

Com base nas simulações realizadas foi possível observar que aproximadamente $24 \%$ do fluido se encontra com velocidade inferior a $3,48 \times 10^{-6} \mathrm{~m} \cdot \mathrm{s}^{-1} \mathrm{com}$ TDH de 4 horas, $1,74 \times 10^{-6} \mathrm{~m} \cdot \mathrm{s}^{-1}$ na simulação com TDH de 8 horas e $1,16 \times 10^{-6} \mathrm{~m} \cdot \mathrm{s}^{-1}$ na simulação com TDH de 12 horas (Figuras 4 a 6), sendo indicativo de zonas mortas no reator. 


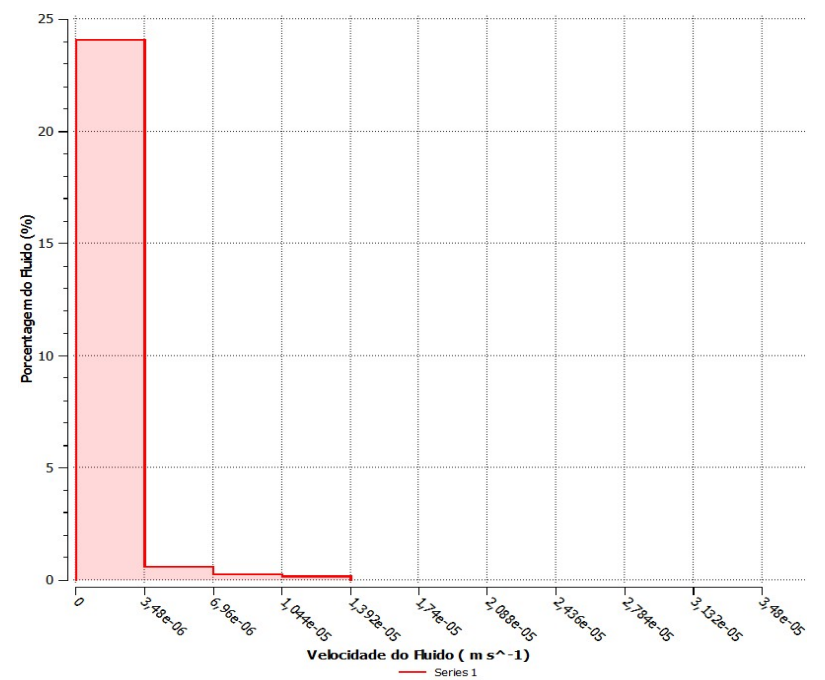

Figura 4: Histograma da porcentagem do fluido (água) com velocidade inferior a 3,48x10-5 $\mathrm{m} \mathrm{s}^{-1}$ para TDH de 4 horas

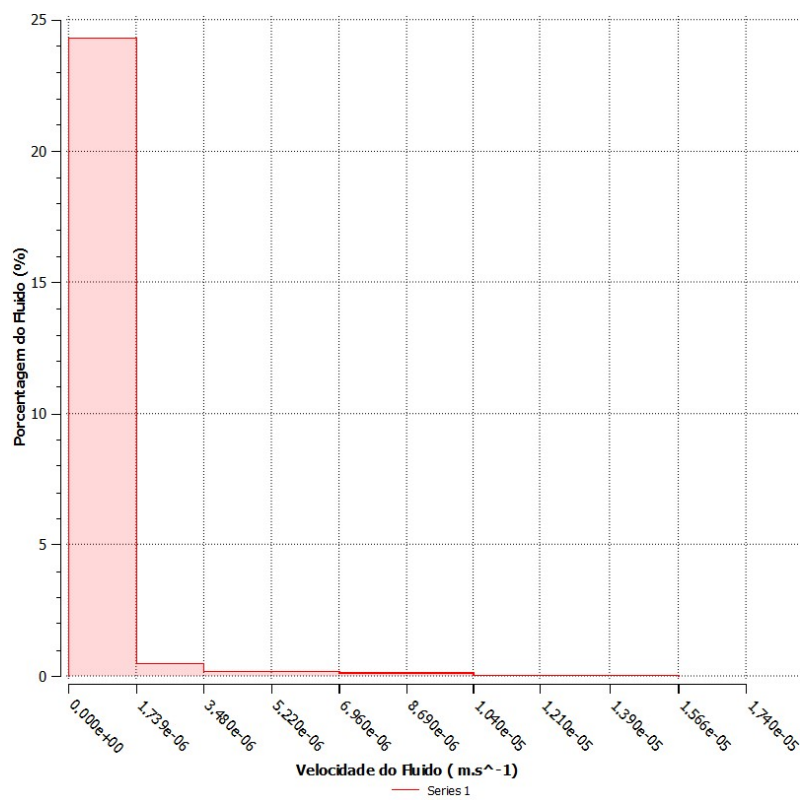

Figura 5: Histograma da porcentagem do fluido (água) com velocidade inferior $1,74 \times 10-5 \mathrm{~m} \mathrm{~s}^{-1}$ para TDH de 8 horas

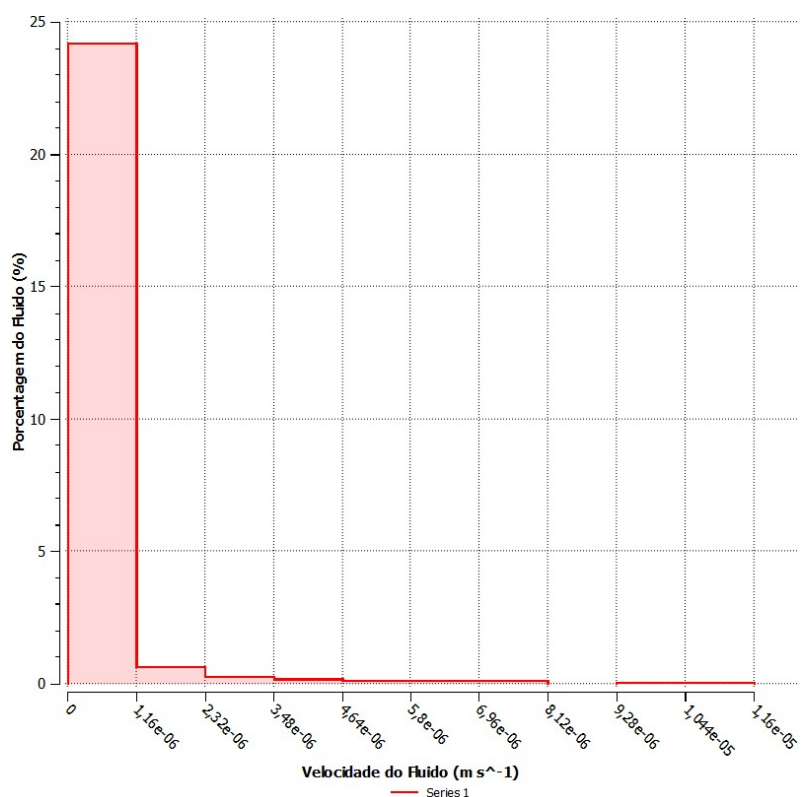

Figura 6: Histograma da porcentagem do fluido (água) com velocidade inferior a 1,16×10-5 m s $\mathrm{m}^{-1}$ para TDH de 12 horas.

Em estudo computacional realizado por Silva (2018) foram obtidos volumes de zonas mortas de aproximadamente 13 \% para parâmetros similares de simulação de um mesmo tipo de reator UAHB, entretanto, tal autor não levou em consideração a existência de lodo no interior do reator e a geometria desenvolvida apresentava uma diferença da utilizada no presente trabalho, já que a saída foi considerada na parte superior do reator e não lateralmente. Esses fatores podem justificar as diferenças dos resultados apresentados nos estudos.

A partir dos perfis de velocidade gerados (Figuras 7 a 9), foi possível observar que as maiores velocidades do fluido (zonas em vermelho) se concentram nas regiões de entrada e saída do reator, o que pode ser explicado pela necessidade de uma maior velocidade da água para que ocorra sua ascensão sobre a coluna de lodo que se forma na parte inferior do reator. Já na região da saída, as altas velocidades 
justificam-se pela redução da área de passagem do fluido. Também é possível verificar na distribuição das velocidades, que conforme ocorre a ascensão da água, a velocidade diminuí e o escoamento tende a se desenvolver preferencialmente na região central do reator.
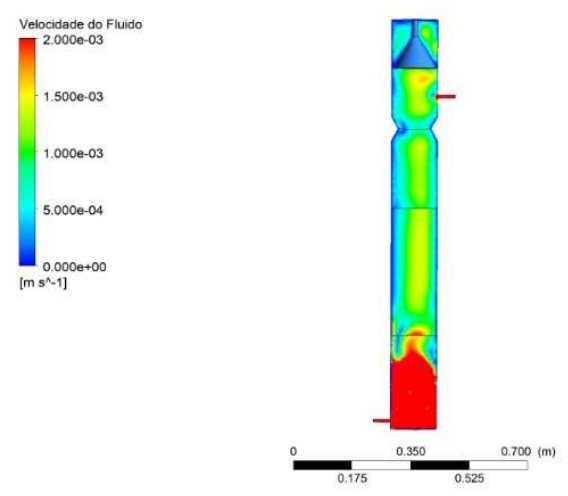

Figura 7: Perfil de velocidade da água no interior do reator UAHB para a simulação com TDH de 4 horas.

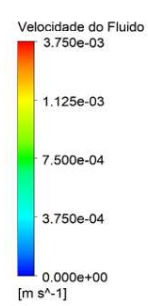

Figura 8: Perfil de velocidade da água no interior do reator UAHB para a simulação com TDH de 8 horas.
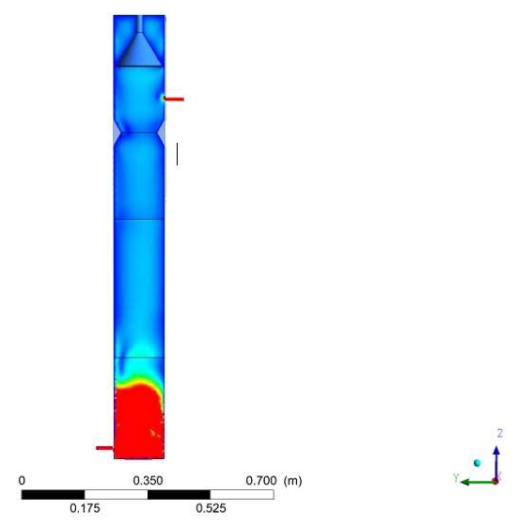
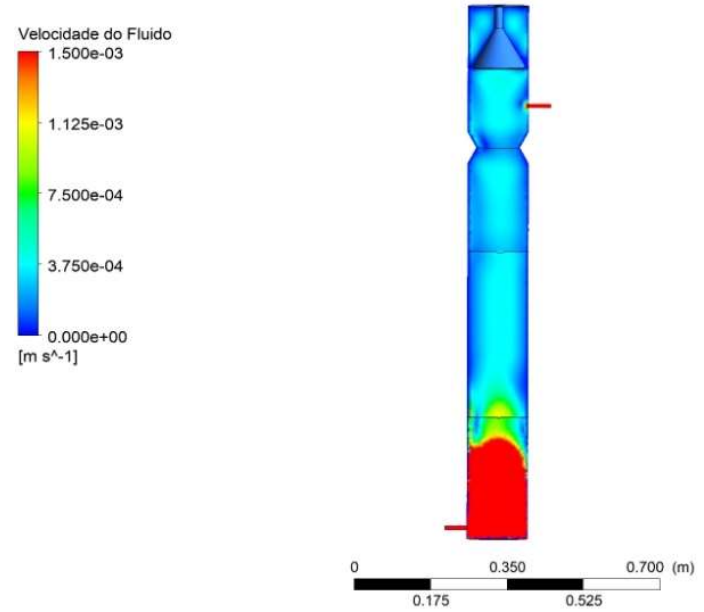

Figura 9: Perfil de velocidade da água no interior do reator UAHB para a simulação com TDH de 12 horas.

\section{CONCLUSÕES}

Com as simulações e comparação com bibliografia é possível verificar a necessidade de considerar as características do lodo presente em um reator UAHB, já que o mesmo pode alterar os caminhos percorridos pelo fluido dentro do reator.

No presente trabalho houve um aumento na porcentagem de fluido com velocidades inferiores as máximas estimadas para os dois TDH's simulados e com os perfis de velocidade das simulações foi verificado que as maiores velocidades ocorrem na faixa de entrada e saída do reator nas simulações feitas por software esses fenômenos podem ter sido influenciados devido à presença de lodo nas simulações, já que na bibliografia utilizada as simulações não levaram em consideração o lodo.

Para trabalhos futuros recomenda-se executar simulações com outros valores de TDH's e execução ensaios físicos com a finalidade de validar os resultados obtidos através de simulações computacionais. 


\section{REFERÊNCIAS}

CHERNICHARO, C. A. L.. Princípios do tratamento biológico de águas residuárias: reatores anaeróbios. Belo Horizonte: UFMG, 1997.

GUIOT, S. R.; VAN DEN BERG, L.. Performance and biomass retention of upflow anaerobic reactor combining a sludge blanket and a filter. Biotechnology Letters, v.6, p.161-164, 1984.

SILVA, L. E. F.. Aplicação da fluidodinâmica computacional no estudo hidrodinâmico de um reator anaeróbio híbrido
(UAHB) abiótico com validação experimental. Monografia (Bacharelado em Engenharia Ambiental) - Universidade Tecnológica Federal do Paraná, Campo Mourão, 2018.

KENNEDY, K. J.; GUIOT, S. R.. Anaerobic upflow bed-filterdevelopment and application. Water science and technology, v.18, n.12, p.71-86, 1986.

TU, J.; YEOH, G. H.; LIU, C.. Computational fluid dynamics: a practical approach. Oxford: Butterworth-Heinemann, 2008.

A CBPC - Companhia Brasileira de Produção Científica (CNPJ: 11.221.422/0001-03) detém os direitos materiais desta publicação. Os direitos referem-se à publicação do trabalho em qualquer parte do mundo, incluindo os direitos às renovações, expansões e disseminações da contribuição, bem como outros direitos subsidiários. Todos os trabalhos publicados eletronicamente poderão posteriormente ser publicados em coletâneas impressas sob coordenação da Sustenere Publishing, da Companhia Brasileira de Produção Científica e seus parceiros autorizados. Os (as) autores (as) preservam os direitos autorais, mas não têm permissão para a publicação da contribuição em outro meio, impresso ou digital, em português ou em tradução. 